\title{
Hygiene Awareness; Improving School Attendance and Participation in Kenya
}

\author{
Susan T. Njau \\ Ministry of Education, Science and Technology, Education Standards \& Quality Assurance Council, Kenya
}

Copyright $(\mathcal{C} 2016$ by authors, all rights reserved. Authors agree that this article remains permanently open access under the terms of the Creative Commons Attribution License 4.0 International License

\begin{abstract}
Prevention of illness amongst school going children is crucial in enabling access and participation in learning. Educational achievements can be linked to healthy behavior, a healthy body and a healthy living environment. There is need to ensure that schools maintain good hygiene in order for the learners to be able to be in school and continue to learn. Quality education entails that children have a holistic learning which includes the emotional, physical psychomotor as well as the academic aspects. Learners should be made to be responsible for their well being both in school and while out of school. It is therefore expected that the school administration, the parents and the community should strive to maintain good hygiene. Schools should put in place measures such as school sanatorium, adequate and appropriate sanitation facilities, provision of clean safe water to ensure that students are in good health.
\end{abstract}

Keywords Hygiene, School Attendance, Participation, Students, Health, Diseases

\section{Introduction}

Kenya is a country found in the eastern part of Africa and borders the Indian Ocean to the South East, Somali to the north east, Ethiopia and south Sudan to the northwest, Uganda to the west and Tanzania to the south. The climate in Kenya varies from tropical along the coast to temperate in the interior and arid in the north and north east parts of the country. Wikipedia [2015]

The primary education in Kenya takes a period of eight years. The children admitted at this level are expected to be between the ages of six to thirteen. It is however possible to get younger or older children attending primary school depending on how early or late the parents enrolled their children in the school. There are two types of schools namely public and private schools. The public schools are owned and managed by the state. This means that the children who attend these schools enjoy the Free Primary Education which was introduced in 2003. The teachers to these schools are government employees and the government provides for tuition fees as well as funds to buy curriculum support materials. The private schools on the other hand are private entities managed by entrepreneurs. Parents who take their children to these schools have to pay for full tuition fees. However these schools adhere to the government policies on education as prescribed. As such all schools in the country have to ensure health standards as prescribed in the health and safety manual to schools.

The mission of the government of Kenya is to create an education and training environment that equips learners with desired values, attitudes, knowledge, skills and competences, particularly in technology, innovation and entrepreneurship, whilst also enabling all citizens to develop their full capacity, live and work in dignity, enhance the quality of their lives, and make personal, social and political decisions as citizens of the Republic of Kenya. Ministry of Education Science and Technology [2012] Education should have a broader outlook in live where the aim should be to empower the learners with skills to enable them survive and not merely getting jobs. Learners should be taught how to cope with life and how to become contributors to the development of their countries but not dependants. It is time education focuses on producing self reliant graduates who are self driven with the right survival skills. This calls for a shift in the curriculum development and delivery where learners become more innovative, practical and adopt new technologies.

The curriculum review in Kenya is in progress and it would be prudent to critically look at ways of ensuring that the new look curriculum prepares learners for the world of work and innovations. The emphasis Kenya has had on performance in National examinations has done a lot of harm to the education achievements. This has led to teachers, parents and other stakeholders to gauge education in terms of only academic achievements. Whereas we appreciate that learners should perform well in the academics, there are however other indicators that determine school performance such as discipline, life skills attainment, socialization and adaptation, health and cleanliness and participation in co curricula activities among others. Due to the over emphasis on the examination performance even the current rich and all 
inclusive curriculum is not well covered. Subjects such as home science, art and craft, music, physical Education and life skills are not taught, yet these are the subjects that can prepare the learners to be self reliant and attain the Practical education for sustainable development.

To this end the country needs to refocus on why education. Education has to be seen as a means to attain relevant knowledge and skills for one to adapt to the environment and the needs of the nation. As the curriculum is reviewed the ministry in charge of education should carry out a lot of sensitization to the stakeholders on why and what education is relevant to the development of the country. This will be in line with the objectives of the vision 2030 which aims to make Kenya a middle income country by the year 2030. In order to do so an area which is really considered to help attain this is the health of the learners, yet without a healthy young population it will be impossible to attain the vision.

It is for this reason that this paper looks at hygiene awareness; improving school attendance and participation in Kenya. This paper will be concerned with the primary school cycle. As search it will be concerned with the attendance and participation of the primary school going children whose hygiene and health is of major concern. This is due to the age of the children who are prone to infections due to the fact that they are still young and require care in order to take charge of their health. The paper will also look at what the government has done to counter this challenge as well as look at how these challenges can be best addressed by all concerned parties.

\section{Importance of School Sanitation and Hygiene}

While developing a manual on school sanitation and hygiene UNICEF highlights the importance of school sanitation and hygiene. It has been proven that in many countries there exists a prevalence of water and sanitation related diseases that cause many children to fall ill and even die. UNICEF [1998] Schools are important when looking at hygiene due to the fact that they are the most important places of teaching and learning for children and they have a central place in the community. The availability of sanitation facilities in schools act as models and the teachers also can function as role models. UNICEF [1998]

In a survey carried out in India, it was established that half of the ailments found were related to unsanitary conditions and lack of personal hygiene. This could be generalized to other areas where sanitation and hygiene are a challenge and hence the need to focus on children. It is worth noting that it is in childhood that children can learn best about hygiene behavior. As future parents what children learn is likely to be applied in their families. Children also take care of their younger siblings and as such they practice what they learn with their brothers and sisters. Therefore, engaging children in the development process as active participants can make them become change agents within their families and communities. UNICEF [1998]. Maintaining of school hygiene is therefore crucial since lack of it schools become risky places where diseases are transmitted. Schools can also pollute the environment in such a way that it causes health hazards for the community at large. It is therefore important for schools to have proper facilities and children should be taught behavior change and proper use of the facilities. UNICEF [1998].

It has been proven that, access to water and sanitation facilities do not by its own, lead to improved health. There is clear evidence of the importance of hygiene behavior in particular hand washing with soap at critical times such as after defecating and before eating or preparing food, greatly reduce the incidence of diarrhea, which is the second cause of death among children under five year old. Washing with soap reduce diarrhea bouts by 50 percent. UNICEF [2003] Good hand washing has also been shown to reduce the incidence of other diseases, notably pneumonia, trachoma, scabies, skin and eye infections and diarrhea related diseases like dysentery and cholera. The promotion of hand washing with soap is also key in controlling the spread of Evian influenza (bird flu). UNICEF [2003].

The Millennium Development Goal number 2A' was to ensure that by 2015 , children everywhere, boys and girls alike will be able to complete a full course of primary schooling. However, inadequate water and sanitation facilities in the school environment have been reported as a major hindrance towards achievement of this goal. Jasper et al [2012].

Most schools in developing countries lack adequate water and sanitation services which has an impact on health and school attendance. Yet, the school environment provides the best environment for children to learn about hygiene and sanitation. It has also been observed that the school Water Sanitation and Hygiene (WASH) interventions improve overall sanitation, hygiene and daily water intake in both educational and non educational environments, Jasper [2012].

According to the World Health Organization (WHO) 11\% more girls attend school when sanitation is available. Blanton et al [2007] performed interventions at seventeen Kenyan schools which provided hand washing and drinking water treatment sources and education of teachers. It was observed that in households where there was water treatment practices sustained for a year, there was $26 \%$ decrease in pupil absenteeism.

O'Reilly et al [2007] while carrying out an evaluation to assess whether a school based water and hygiene intervention had impact on student's knowledge and parents adoption of safe water and hygiene practices in Nyanza Province in Kenya noted that students learnt correct water treatment and when to wash hands . On the other hand $14 \%$ of parents reported they were treating their water. From 2004 to 2005 there was a decrease in school absenteeism in the September-November in nine project schools by $35 \%$. 
During the international year of sanitation, UNICEF highlighted why improved sanitation is important for children. Sanitation and hygiene are key to child survival, development and growth. By the year 2008, improved sanitation had not reached 2.6 billion people in the developing countries. Almost 980 million of who were children under eighteen years old. UNICEF [2008] This is a big segment of the population especially because as a result, millions of children die from preventable diseases. There is therefore need to pay attention to sanitation and hygiene in schools.

Some of the benefits of improved hygiene do not only impact on the children but on the communities and the economies of the nations. Where adequate sanitation is provided there are improvements in; Lower morbidity rates in children, Lower mortality rates due to diarrhea. Better nutrition among children, cleaner environments, improved water supplies, better learning and retention among school children among others. It is evident that sanitation is vital for health. Poor hygiene and lack of access to sanitation lead to about 88 percent of deaths from diarrhea. If the world had attained the MDGs in Africa, 173 million cases of diarrhea would have been avoided. UNICEF [2008]

Sanitation also leads to social development. Schools that have good sanitation attract and retain children especially girls. One in four girls does not complete primary schools, compared in one in seven boys. Girls carry the greater burden of water collection which requires many hours; in addition girls in menstruation age are reluctant to attend school where facilities are not conducive. This means that healthy children are the ones who attend school and gain from it. UNICEF [2008]. The World Health Organization estimate that, 194 school days would be gained annually if the MDGs are met. UNICEF [2008]

There is also evidence that children with worm infestations perform poorly in learning ability tests, cognitive function and educational achievements and that infected children attend school only half as much as their healthy peers. UNICEF [2008]

Other benefits of sanitation include improved economies and environments.

The importance of sanitation in schools cannot therefore be underrated as the benefits are not only of assistance to the individual child who is able to concentrate in school and attain knowledge but also to the community and the country. The country saves on funds for medication and is able to minimize mortality which brings economic gain to the nation by producing enough man power. A healthy nation will positively contribute to the economic development of the country. Education for sustainable development has to ensure that the learners are not only healthy but ensure to remain healthy.

\section{Health Issues in Children}

\subsection{Health Ailments That Affect School Attendance and Participatation}

Diseases that affect education are prevalent. The number of children affected are staggering, half of school children have anemia, half of them are stunted in growth as a result of under nutrition, one third of them have worm infections. The effect of these diseases on education is big and the cumulative worldwide loss of intellectual potential is enormous. Freeman et al [2008] Most of the children affected are found in poor countries. It is difficult for children from rich communities to contract HIV from their mothers. Few of them die from measles, have worm infections or are stunted in growth. On the other hand children in poor communities not only lack in education for many reasons but in addition poor health and nutrition is additional barriers between them and their educational potential. Freeman et al [2008].

Freeman et al [2008] also states that, there are an estimated 1,200 million children of school going age worldwide, with 88 percent of these living in poorer countries. It is this group that is at risk of various ailments. 25 to 30 percent of school age children are infected with one or more of the major helminthes species. These are the infections with parasitic worms such as round worm, whip worm, hookworm and the schistosomes. An estimated 20 percent of disability adjusted years lost due to communicable diseases among school children are a direct result of intestinal worms. Malaria is responsible for 10 to 20 percent of all mortality cases in school going children. 13 million children under the age of 15 have lost their mother or both parents to AIDS. 48 to 56 percent school age children are stunted and 34 to 62 percent are underweight. 53 percent of school age children suffer from iron deficiency anemia. Iodine deficiency disorders affect an estimated 60 million or 5 percent of school age children and vitamin A deficiency affects an estimated 85 million or 7 percent of the school age children. Vitamin A deficiency is a public health problem in 118 countries in Africa and South -East Asia, hitting mostly children and pregnant women. Between 100 and 140 million children are vitamin A deficient and an estimated 250,000 to 500,000 vitamin A deficient children become blind every year, half of them dying within twelve months of losing their sight. When children lose their sight their learning is affected more so if they come from developing countries. This is due to lack of adequate resources and institutions for special needs education.

Diette GB et al [2000] reported findings of how nocturnal asthma in children affects school attendance, school performance and parents work attendance. The research was carried out by Jama pediatrics in the North East and Mid West United States. The study was carried out to 438 children, 74 percent were white and 19 percent were black. It was established that the presence of nocturnal asthma symptoms in children was associated with decreased school attendance and performance. Nocturnal asthma in children could be more disruptive to children than had previously 
been recognized. That approximately one half of children with even a small number of nights awakened in a four week period missed school and had their education suffer.

In an article putting menstrual hygiene management on to the school water and sanitation agenda, Marni Sommer [2010] noted that educating girls plays an important, role in the economic development, civil society formation and population health of nations. Despite the continued call for attention of girl's education, schools throughout low income countries continue to lack the basic water and sanitation related facilities essential for adolescent girls who on monthly basis must manage their personal menstrual hygiene in schools that lack adequate latrines or any latrines. They also lack sufficient supply of water and a mechanism of disposing the sanitary towels in an appropriate way. These conditions are to be found in sub -Sahara Africa, Asia and other regions. Lack of these facilities keeps girls away from school at least four days in a month. This has a great impact on the performance of girls who not only feel secluded but also disadvantaged in their school achievements.

While carrying out a study on how lack of sanitary towels reduces school attendance in Kenyan slum Chebii [2012] noted that "Limited access to safe and affordable, convenient and culturally, appropriate methods for dealing with menstruation has far reaching implications for rights and physical, social and mental well being of many women and adolescent girls in Kenya. It undermines sexual and reproductive health and well being and has been shown to restrict access to education.

In Kenya, menstruation is not only a health concern, but an educational policy concern. It is therefore a key factor if the country is to achieve the Millennium Development Goals (MDGs), of eliminating gender disparity in primary and secondary education by 2015, Chebii [2012].

The study established that, menstruation causes Kenyan adolescent girls to lose an average of 3.5 million learning days per month. UNESCO also estimates that one in 10 African adolescent girls miss school during menses and eventually drop out of school. This is a result of in accessibility of affordable sanitary protection, the social taboos related to menstruation, and the culture of silence that surrounds it

According to Kottoh [2008], menstrual blood is considered dirty and harmful. Hence girls who are menstruating are restricted from participating in some activities for fear that they will contaminate things that they touch. The girls may not also be allowed to cook or clean dishes and are also re restricted from playing with others. As a result these girls are stigmatized and a perception that menstruation is shameful is created. Due to lack of sanitary towels girls are made to stay at home to avoid staining their clothes.The physiological and symptomatic challenges that go through during their menstrual cycle also hinder them from accessing education. The tension, depression, tiredness and irritability affect the way adolescent girls cause sudden swing moods and this affects the way girls relate to other students in school and their teachers. Dalton [1979]
Sharma et al [2010] argues that, at the onset of menstruation, females between the ages of 15 and 25 can experience dysmenorrheal, which featured as the most common problem among adolescent girls and often results in prolonged bed rest and girls missing both classes and other social activities.

According to several research reports from the African population and Health Centre (APHRC) in Kenya's urban informal settlements, the Forum of African Women Educationists (FAWE), individual researchers and other Non Governmental Organizations in Kibera, Korogocho, Mukuru and Kiandutu informal settlements, showed that there exists limited knowledge about the biological process of menstruation. The research also indicated that, menstrual blood was considered as unclean and harmful.

The research also showed that most women did not have access to pads. Women and girls mostly used cotton wool, cloth, tissue paper and even pages from exercise books as well as sponge from old mattresses. In some rural areas, girls used rags, leaves, cow dung or dug holes on the ground to sit on for the whole period of menstrual flow. Chebii [2012]

The inaccessibility of menstrual products resulted in embarrassment, anxiety and stigma. Girls described this period as a time for discomfort at school, leading to low concentration. Chebii [2012]

The Federation of Africa Women Educationists (FAWE) [2006] stated that lack of a conducive environment was a leading cause of the low retention of girls in school. Poor sanitation was cited as a leading determinant of whether adolescent girls turn up for class or not.

In 2003, the UN Secretary General, Kofi Annan stated that "there is no tool for development more effective than the education of girls. No other policy is likely to raise economic productivity, lower infant and maternal mortality, improve nutrition and promote health" [cited in UNICEF, 2008]. Although girl's enrollment rates in sub-Sahara Africa have improved, large inequality in primary education remains UN [2012]. Emphasizing linkages between girl's absence from school and poor sanitation provision, several studies in Sub-Sahara Africa have highlighted every day challenges associated with managing menstruation in school environments. Jewitt and Ryley [2014]

In a study carried out in Tanzania Sommer [2010] indicated difficulties associated with lack of access to private toilets with water supplies, sanitary products, painkillers for menstrual cramps, and spare clothes if leaks occur. Long school hours (typically 8 in Kenya) that increase the risk of leaks, teasing by boys around the toilet areas add to shame and embarrassment experienced by girls. Girls may also have odour where it is difficult to change the towels and again this leads to discomfort and stigmatization. Muito [2004] The constraints related to menstruation make Kenyan girls view menstruation as the most significance social stressor and barrier to schooling. McMahon et al [2011]

A paper on Anemia and school participation by Gustavo indicated that anemia is among the most widespread health problems for children in developing countries. The paper 
evaluates the impact of randomized health intervention delivering iron supplementation and de-worming drugs to Indian preschool children. At baseline, 69 percent were anemic and 30 percent had intestinal worm's infections. As a result weight increased among assisted children, and preschool participation rates rose by 5.8 percent and absenteeism was reduced by one fifth. These results contribute to a growing view that school based Heath programs are an effective way of promoting school attendance in less developed countries. Gustavo et al [2006].

The journal of epidemiology and community health features a paper on the association between school attendance, HIV infection and sexual behavior among the young people in rural South Africa. The objective was to investigate whether the prevalence of HIV infection among young people, and sexual behaviors associated with increased HIV risk, are differentially distributed between students and those not attending school or college. The conclusions of the study were that attending school was associated with lower risk sexual behaviors and, among young men, lower HIV prevalence. That secondary school attendance may influence the structure of sexual networks and reduce HIV risk; therefore Maximizing school attendance may reduce HIV transmission among young people. Hargreaves J [2008].

The Kenyan situation in as far as health of children of school going age indicates that children are affected by the common diseases that keep them out of school. A study assessing the educational impact of malaria prevention in Kenyan schools was carried out in 2008. Malaria poses a big public health burden. Although malaria greatly affects children under five, older children including those attending school are at risk of mortality and physical morbidity. In addition malaria contributes to school absenteeism, poor cognition and school performance. Brooker et al [2010].

Malaria (both clinical and a symptomatic) is a major cause of anemia in school -age children. Kurtzhals et al [1999] While marking the world malaria day the Business Daily indicated that Kenya is greatly concerned with malaria infections and reported that, malaria is Kenya's most devastating killer as it claims the lives of almost half a million children below the age of five each year. Business Daily [24/4/2015]

a study to evaluate the primary school de-worming project was undertaken in Busia district, Kenya by the International Child Support in cooperation with Busia district Ministry of Health between 1997 to 2001. The sample targeted 75 primary schools and 30,000 students. Busia district is located in western part of Kenya and is adjacent to Lake Victoria. Bundalangi and Funyula areas of the Busia district have some of the country's highest helminthes infection rates. This is due to the proximity to the lake and other worms are transmitted through the soil, while others are transmitted through contact with or ingestion of fecal matter. This can happen where children have no access to toilets in school or at home. One quarter of Kenyan student absenteeism is attributed to abdominal pains, which are likely due to intestinal helminthes infections. In addition older children may miss school to look after siblings sick with helminthes infections. Government of Kenya [2001]

The results of the study were that deworming reduced serious worm infections by half amongst children in the treatment groups. Pupils that received treatment reported being sick less often, had lower rates of severe anemia, and showed substantial height gains, averaging 0.5 centimeters. De-worming increased school participation by at least 7 percentage points, which equates to one quarter reduction in school absenteeism. When younger children were de-wormed, they attended school 15 more days per year, while older children attended approximately 10 more school days per year. Speaking when he met the world program head Michael Kremer, Mr. Odinga, the then Prime Minister of Kenya, said that the government was committed to de-worm school children, terming it as an effective health intervention in improving students participation in schools. $\mathrm{He}$ further said that worms were as responsible for absenteeism in schools as is the cost, distance and lack of facilities. "Worms undermine the health of children and affect their ability to learn, we are committed to the program me of de-worming children, we still need more help to fight the problem Parasitic worms limit nutrients absorption and cause internal bleeding, leading to anemia and malnutrition. As a result children are either too sick or too tired to concentrate in class or attend school. Business Daily [2009]

A study in Kisumu Kenya, to seek the feelings and opinions of school girls and encourage them share their lived experiences and aspirations in the subject of menstruation, nine schools were visited among them one private school and one secondary school. Quality time data from the girls and teachers in the study area clearly suggested that improved access to sanitary pads could address some key emotional and practical problems underlying girls' absenteeism.

Kenyan adolescent girls miss approximately 3.5 million learning days per month due to lack of funds to purchase sanitary pads. This erodes their self esteem and contributes to higher dropout rates and in many cases makes such girls vulnerable to early marriages.

School going children are also affected by jigger infestation. According to Ahadi Kenya an NGO which has been working to eliminate the menace, jigger infestation is wide spread in Kenya; however some areas are more prone than others. Many children in Gatundu North and south are living in pain due to jigger infestation. Children as old as thirteen years have never known how to walk or even attend school. In msabaha location, Malindi district, more than 3000 children are jigger infested. Most of the children treated in a camp organized by Safaricom ltd and Ahadi Kenya had both their legs and hands heavily infested. This would make it difficult for the children go to school. Jiggers have negatively affected education standards and also caused high school dropout rates. The jigger infestation is wide spread and through Ahadi Kenya, many organizations have joined the fight. These include Safaricom ltd., Laico Regency hotel, politicians, local leaders and NGOs. Ahadi Kenya [2007]. 
To date 50 corporate have joined the fight so has the First Lady of the Republic of Kenya Mrs. Margaret Kenyatta. Ahadi Kenya [2014]

Other ailments that may keep children away from school include cholera, whereby occasionally there are out breaks due to poor hygiene and lack of clean water. In 2010 there was an outbreak of cholera in Kuria west district which spread to the neighboring Migori district. Onyango et al [2010]

The Turkana region also experienced chorea outbreak in 2010 which was caused by flooding. Children infected by cholera may not be able to attend school since this disease involves serious diarrhea which weakens the body, if not treated in time it leads to death.

Any type of ailment affecting children will in one way or other keep children out of school and even though they may attend they will not have full concentration.

\subsection{Government Intervention in Health and Hygiene in Schools}

Whereas schools have a role to play in ensuring the children are in good health and observe hygiene, the government has to play its role as well. The government has to provide healthy services to ensure children are treated when sick. The government is also expected to help schools access clean water either through its own effort or working with the parents and other stake holders. The government should also give policy guidelines on hygiene and health safety in schools. The government of Kenya through the ministry in charge of education has developed a safety and standards manual for schools in Kenya. Safety standard number three is on health and hygiene safety. The government recognizes that the health of learners and their learning achievements are closely related and that learners can reap maximum benefits from teaching and learning if they are healthy. The overall objective of the school health program me is to promote, maintain and contribute to the knowledge of learners and advise about health living. Church World [2008] As such the school safety standard 3 states that the school should provide an environment that nurtures positive health in order to protect, promote and improve health for all. Church World [2008]

In 2009 the Ministry of Health and Sanitation and the Ministry of Education developed the National School Health Policy. The vision of the policy is "A healthy, enlightened and developed nation" and the mission is "to work together in planning, designing and implementing sustainable quality health interventions across the education sector" and the main goal is "to enhance the quality of health in school communities by creating a healthy and child friendly environment for teaching and learning. Ministry of Public Health and Sanitation and Ministry of Education (MOH\&S and MOE) [2009]

The government recognizes the importance of good health and hygiene as contributors to attainment of education for all. The Republic of Kenya recognizes that diseases, disability and ill health are major impediments to national development and poverty reduction. The government is committed to ensure the health of children who make about 50 percent of the population and who suffer from various ailments, nutritional deficiencies and morbidity. The health concerns impede effective learning and realization of their full productive potential. MOH\&S and MOE [2009] The health policy attributes ill health is as a result of poor quality water, sanitation, hygiene, poor housing, parasitic infections, infectious diseases, macro and micronutrient deficiencies, HIV and AIDS and sexually transmitted infections. In addition problems encountered, especially in adolescence such as unplanned pregnancy, substance use and abuse, sexual harassment and other forms of abuse also contribute to poor health of children. Many school environments are risky resulting to injuries and accidents. MOH\&S and MOE [2009]

The government of Kenya seeks to improve health and education of children as it is aware that improved health allows for better physical and cognitive development in children and therefore produces a more productive population. The policy defines a comprehensive school health program me (CSHP) to enable the government address the health and education needs of learners and their families. The policy advocates for the establishment of health program mes in the school system. Some of the objectives are; to promote the teaching of positive values and life skills, promote gender related issues, enhance child rights and protection, promote good nutritional status of school children, promote disease prevention and control; promote hygiene and, sanitation and use of safe water amongst others. MOH\&S and MOE [2009]

The Ministry of Education in conjunction with UNICEF has introduced the concept of Child Friendly Schools (CFS). A Child Friendly School is one where the environment is conducive to learning, the staff is friendly and the health and safety of the children are adequately met. Therefore it is a school which is community -based, takes cognizance of the rights of children, irrespective of gender, religious and ethnic affiliation and any other differences. A CFS should provide safe spaces for girls and boys to learn effectively. It is free from abuse, guarantees safety, respects diversity (girls, boys, children with special needs, HIV \& AIDS infected and affected) it promotes guidance and counseling relating to key issues affecting learners such as drugs, early marriages, early pregnancy, gender, masculinity and femininity . The schools should promote physical, mental and emotional health and nutrition. There should be adequate separate sanitary facilities for girls and boys, as well as safe drinking water. UNICEF [2010)] The CFS program me is being implemented in a number of primary schools around the country with ultimate aim of being implemented in all primary schools.

The Sexual Offences Act No. 3 of 2006 is an act of parliament to make provisions about sexual Offences their definition and protection of all persons, from harm, unlawful sexual acts, and connected purposes. National council of law 
reform [2009]. This law protects all persons including children. It is very specific with issues of children or minors and the conviction for those who defile children is very stiff. "A person who commits an Offences of defilement with a child aged eleven years or less shall upon conviction be sentenced to imprisonment for life" the conviction for defilement of a child between the age of twelve and fifteen is a jail term for twenty years and those who defile children of between sixteen and eighteen get fifteen years. National Council of Law Reform [2009]

The Children's act, 2001 is an act of parliament to make provision for parental responsibility, adoption, custody, maintenance, guardianship, care and protection of children; to make provision for the administration of children's institutions; to give effect to the principles of the convention of the rights of the child and the African charter on the rights and welfare of the child and connected purposes. Laws of Kenya [2001] The government by passing this act was in cognizance on the rights of the child. It is the responsibility of the government and the family to ensure the survival and development of the child. Right number nine in the act is the right to health care and states that "Every child shall have a right to health and medical care the provision of which shall be the responsibility of the parents and the government. Laws of Kenya [2001]

The constitution of Kenya article 43 states that every person has a right to; the highest attainable standard of health, which includes the right to health care services, including reproductive health care; to accessible and adequate housing and reasonable standards of sanitation; to be free from hunger, and to have adequate food of acceptable quality; to clean and safe water in adequate quantities; to social security and to education. The constitution commits the government to provide education and health to all Kenyans including children.

As already noted the education of girls is affected by lack of sanitary towels and facilities. The government after realizing this gap introduced the sanitary towels program me which started in 2012 with a budget of kshs.240 Million. This money was to benefit 443,858 girls in public primary schools drawn from 82 targeted districts. The Financial Year 2015/2016 will have an increase with Kenya shillings. 200 Million to expand and sustain this program me. This program is implemented by the ministry in charge of education.

The National Campaign against Drug Abuse (NACADA) Authority in Kenya was established by an act of parliament on 24th July, 2012. The authority's main focus is on demand reduction, which involves providing preventive education, public awareness, life skills, treatment, rehabilitation and psycho-social support to the general public. It also contributes towards supply suppression through policy formulation and capacity building. www.nacada.go.ke [2015] Children are the ones mostly affected by substance and abuse and the role of NACADA cannot be underrated to ensure children are protected. Children dropping out of school or not performing well due to drugs have been recorded in Kenya. We have children who are taking alcohol and this is prone in the central parts of Kenya. Substance abuse is wide spread but more prone in the major towns and in alarming levels in Mombasa and Malindi. The children are left helpless and at times they lose their lives.

As already noted the Ministry of Education, Science and Technology in collaboration with other stakeholders has implemented the de-worming program me. Already 6.4 million children have been declared worm-free and are ready to learn through the Kenya National De-worming program me. This was announced on $4^{\text {th }}$ August 2014; by evidence action de-worm the world initiative and the Kenya government. De-worming took place in nearly 16000 schools in 28 counties that are endemic for parasitic worms. Evidence action [2014]. The government launched a national, school based de-worming program me in 2009 where 3.6 million children were de-wormed in 45 sub counties. The program me was re-launched in 2012 and targeted 5 million children and 11,000 schools. However, the drive was able to surpass the national target.

\section{Solutions and Recommendations}

Children in schools are faced by many challenges related to health. As already noted various ailments such as malnutrition, malaria polio, and intestinal worms drug and alcohol abuse undermine the physical and emotional well being of learners. Children are also affected by issues related to HIV and AIDS, as well as sexually transmitted diseases. Other ailments mentioned are diarrhea, pneumonia and acute respiratory diseases. UNESCO [2010] This calls for governments, educationists and stakeholders to come up with policies to involve the learners to be participants in improving their health. The learners should also be trained on how to maintain their own health and hygiene in the environments they live in. This could begin by making them understand what health is and what hygiene is.

The new public Health approach focuses on preventing diseases not just curing them. This approach pays attention to economic in equalities, social problems and environmental issues that cause many diseases. It tries to address the root causes of diseases. UNESCO [2010] This approach would require children to learn the root cause for the diseases and then look for ways of avoiding the causes. As already noted children are greatly affected by diseases brought by unclean water or lack of washing hands after using the toilet or before eating. This then would require the teachers to train the children about using clean water and washing hands with soap after visiting the toilet and before eating. In areas where water is scarce, innovative ways should be adapted to ensure there is provision of water for washing hands. Children should be taught water can be purified by boiling it before use.

Good health and nutrition are both essential inputs and important outcomes of basic education. UNESCO [2010] As such a healthy safe and secure school environment can help protect children from health hazards, abuse and seclusion. 
For this reason effective health programs developed as part of community partnerships should be put in place. This will help cater for children who join school from poor and disadvantaged households. An effective education system should therefore ensure that children are healthy and able to learn.

Schools should therefore improve the health and learning of school children through school based health and nutrition program mes. Schools could introduce school feeding program mes with assistance from government and well wishers. The government in liaison with partners could have special program mes related to maintaining health and hygiene in schools.

The ability of a child to attain full capacity is related to good health, good nutrition and appropriate education. Good health and good education are not ends in themselves but also means which provide individuals with a chance to lead productive and satisfying lives. As such school health is an investment in a country's future and in the capacity of its people to thrive economically. Hence an effective school health, hygiene and nutrition program mes are of great benefit to the society. UNESCO [2010]

School communities should therefore endeavor to involve the children, teachers, parents and management in promoting school health programs. The school management should be familiar with government policy and guidelines in ensuring the health of the learners. The teachers should play their part as role models by constantly reminding the children on the benefits of maintaining good hygiene in their environments. They should also practice what they teach so that children can learn through observation. Programmes to promote school hygiene such as cleaning competitions, assigning duties to children to maintain their premises, water conservation, proper use of sanitary facilities and general body hygiene should be enhanced in the school and at home.

Schools could create hygiene and learning plans to hand washing, face washing, blowing and wiping their noses, menstruation management. Schools should also try to provide water and soap as much as possible. It is also the responsibility of the schools to provide Health care to children such as support with taking medication and supporting health programs like immunization. Victoria State government [2014]

Water and hygiene are closely related. Good health depends on good hygiene. Hygiene refers to conditions and practices that help maintain health and prevent spread of diseases. WHO [2015] School children should wash their hands, should drink clean and safe water and girls require adequate water especially during menstruation. The situation on the provision of water is however wanting. More than 850 million people in the world lack access to water supply and more than 2.5 billion lack access to sanitation. WHO \& UNICEF [2010] Improved school water treatment and hygiene (WASH) conditions such as increased water quality, and quantity hygiene education, provision of soap, improved latrine access to cleanliness may reduce pupil absence by providing services and learning environment that appeals to children. Freeman et al [2012].

The Beech field School Health policy highlights what the school should do to ensure health and hygiene for the children. Some of the areas covered are; children who get accidents in school, that they should first get first aid and parents informed through a note and notified through telephone child who gets sick in school is assessed by a senior teacher who decides whether the child goes home or informs the parents. Parents are requested to keep children home if they are infected and other parents are notified in case of a risk in infection. Children infected by diarrhea should also stay home until 24 hours has lapsed since last attack. Cuts and open wounds should be cleared and covered. First aid kits are available and under the senior teacher. There are guidelines on to how teachers handle prescription medicine. The school also holds discussions on health and hygiene with parents. Smoking and dogs are not allowed in the school compound. To prevent spread of infections adults should ensure that good practices are observed, personal hygiene such as washing hands after using the toilet, avoid sharing earrings, a box of tissue is available and children encouraged to blow their noses when necessary, soiled tissue is disposed off hygienic ally, children to shield their mouths when coughing and that hygiene rules related to bodily fluids are followed with particular care to all staff and volunteers. Parents should also provide sufficient suitable sanitary for girl as required. There are regulations on handling food and cleaning and clearance of dangerous objects and materials. The pupils have responsibilities to ensure their own health. They should wear school uniform, PE kit for sports and exercise, indoor footwear when in the school building and appropriate footwear for outdoors. Earrings should be removed or covered during PE and students should observe all safety rules.www.beechfield.herts.sch.uk $>\mathrm{PDFs}>2 \mathrm{n} .$. [2015].

\section{Conclusions}

It is evident that good health is related to school attendance and achievement. It is also evident that when any one is sick they cannot be very productive. The government, schools and parents have to play their role in ensuring the health of the children is maintained. The government invests in education so as to ensure supply of skilled labor, entrepreneurs and developers to run the economy. The government spends a lot of money in curative medicine and these funds could be spent in other sectors of development if sickness is avoided.

School children bear the biggest burden of some of the most common diseases that affect education. Strategies to control disease among school children are particularly effective. De- worming children every six months or so can prevent worm infection illness. Regular iron supplementation can help prevent the prevalence of anemia. Since majority of worm infections are concentrated in school age population, treating these children is an effective way to 
reduce the global impact of these diseases.

School absenteeism is common and undermines educational efforts. Clearly children who attend school less frequently are less likely to fulfill their educational potential. Chronic absenteeism can have most serious effects when it leads to grade repetition or drop out from school. Freeman et al [2008].

In order to keep the children in school all stakeholders must play their role by ensuring the health of the children is safe guarded. When children miss school they cannot get quality education. Without quality education it would be difficult to sustain development. Schools should therefore endeavor to provide a holistic education giving children life skills which include good health for sustainable development.

\section{REFERENCES}

[1] Adams, J, Bartern, J, Charrier Y, SIMS, S, EdsWorld Health Organization Water Sanitation and hygiene standards for schools in low cost settings. Geneva, Switzerland.; [2009]

[2] Ahadi Kenya Trust, Activities. Jigger-ahadi.org[2015]

[3] Blanton, E; Ombaki, S; Oluoch, G, Mwaki, A Wannemuehlere, K; Quick, R. Evaluation of the role of point of use water treatment and hand wash in schools and households- Nyanza province, Western Kenya. AM. J. Trop Med. Hyg. [2007]

[4] Brooker S, Okello G, Njagi K, Dubeck MM, Halliday KE, Inyega $\mathrm{H}$, Jukes $\mathrm{MC}$; improving Education Achievements and anemia of school Children: Design of a Cluster Randomized trial of a school- based Malaria Prevention and Enhanced literacy instruction in Kenya. Pub med commons [2010]

[5] Business daily 2009

[6] Business Daily 2015

[7] Chebii J. S. Menstruation and Education; how lack of sanitary towels. Reduces school attendance in Kenyan slums. Cosisaopen society initiative for Southern Africa. Osisa.Org [2012].

[8] Church World Service, Safety Standards Manual for Schools in Kenya [2008]

[9] Dalton, K Once a month: the menstrual syndrome; Its causes and consequences. Stanford: Harvester [1979]

[10] Diette, GB; Mark son L, Skinner A, Nguyen TH, Bergstrom PA, Albert WU, Nocturnal Asthma in Children Affects School Attendance, school Performance, and parents' Work Attendance, Arch Pediatri Adolesc Med.2000; 154(9):9283-928

[11] Evidence Action, De-worm the World Initiative, online www.evidenceaction.org [2015]

[12] Freeman MC, Leslie EG, Robert D, Shadi S, Muga R, Bruback B, Rheigans R Assessing the Impact of a School Based Water Treatment, Hygiene and Sanitation Programmme on Pupil Absence in Nyanza, Kenya: a cluster-randomized trial. A
European Journal TMIH [2011].

[13] Gustavo JB, Miguel E, Charu PS, Anemia and School Participation; Journal of Human Resources: University of Wisconsin. [2006]

[14] Hargreaves J, The Association between School Attendance, HIV Infection and Sexual Behavior among Young People in Rural South Africa. Journal of Epidemiology and Community Health. [2008].

[15] Jasper C. J. Thauh Tamle, Bartram water sanitation in schools. A systematic review of the Health and Educational outcomes. International Journal of Environmental Research and public Health. . [2012]

[16] Kottoh, MA. Traditional Menstrual Practices: sexual and Reproductive Health for Girls. Institute of African Studies Research Review NS 24:

www.sabinet.co.za/abstracts/anfastud/in-afstud-[2010]

[17] Kurtzhals AL, Addae MM, Akanmori BD, Dunyo S, Koram KA,Appawu MA, Nkrumah FK and Hviid L, Anemia caused by Asymptomatic Plasmodium Falciparum Infection in Semi Immune African School children. Oxford University press, Oxford journals volume93, issue 6.pp 623-627

[18] Laws of Kenya, The Children Act 2001

[19] Laws of Kenya, The Children's Act 2001. Government Printer [2002]

[20] Laws of Kenya, the Sexual Offences Act. National Council of Law Reporting [2006]

[21] Marni Sommer, Putting 'Menstrual Hygiene Management' into the School Water and Sanitation Agenda. Research Gate, Waterlines 09/29(4):268-278:10.

[22] Ministry of Education and Ministry of Higher Education Science and Technology: Sessional Paper No. 14 of 2014, on reforming Education and Training Sectors in Kenya.[2014]

[23] Ministry of Education Safety Standards Manual for Schools. Church World Service, (2008).

[24] UNICEF ,Ministry of Education Manual in child Friendly Schools [2010]

[25] Ministry of Public Health and Sanitation and Ministry of Education, National Health Policy [2009]

[26] Muito M, (2004). Gender Equality in the Classroom: Reflections on Practice. Paper [2004].

[27] Nacada, Baseline Survey on Perception of Magnitude and Effects of Alcohol and Drug Abuse- Central Kenya Region online available from https://www.nacada..go.ke

[28] O’Reilly CE; Freeman MC; Ravani M; Migele j; Mwaki A; Ayalo,M; Ombeki S; Hoekstra, RM; Quick, R. The impact of a school based save water hygiene program me on knowledge and practices of students and their parents: Nyanza Province Western Kenya 2006. Cambridge University Press, Epidemiology and infection/volume136/issue 01pp 80-91, [2007].

[29] Onyango D, Karambu S, Abade A, Amwayi S, Omolo J High Case of Cholera out Break In Western Kenya, The Pan African Medical Journal online available: http://creative commons.org/licence/by/2.0

[30] Sarah Jewitt, Harriet Ryley, It Is a Girl Thing ; Menstruation, 
school attendance, Spatial Mobility and Wide Gender Inequalities in Kenya. Geoforum Vol. 56 137-147. [2014]

[31] The Basic Education Act (2013) on reforming education and training sectors in Kenya.

[32] UN, Un 2012 Millennium Development Goal 3: Where Do We Stand? Chatty://www.undp.org/content>

[33] UNICEF ,A Manual on School Sanitation and Hygiene. [1998]

[34] UNICEF, Girls Education Campaigns. <http;// www.Unicef.org/ educational/ campaign.html>, [2008]

[35] UNICEF , Why Improved Sanitation is Important for Children UNICEF (2003) Water Sanitation and Hygiene, [2008]
[36] United Nations. (2013). The Millennium Development Goals report. New York, NY, USA [ 2010]

[37] Uriah,. The Constitution of Kenya. National Council for Law Reporting [2010]

[38] Wikipedia the free encyclopedia, Geography of Kenya [ 2015]

[39] Victoria State Government, school policy \& Advisory Guide, online available: www,education.vic.gov.au $>$ school $>$ spag [2015]

[40] World Bank, Gender Equality and Development. http: wdronline.worldbank.org/> [2012]

[41] www.beechfield.herts.sch.uk $>$ PDFs $>2$ n...,Health \& Hygiene policy: addendum to health \& safety Policy [2015] 